\title{
Mallarmé REDivivo EM EduARdo Guimaraens
}

ELLEN GUILHEN*

\section{Resumo}

Publicado em 1916, o livro de poemas Divina Quimera, de Eduardo Guimaraens (1892-1928), estabelece, em suas inúmeras referências, relações com as obras e os textos críticos de Charles Baudelaire (1821-1867), Edgar Allan Poe (18091849), Stéphane Mallarmé (1842-1898), entre outros. Sua configuração, calcada na alternância de caráter das cinco partes, permite-nos aproximá-lo da forma musical fantasia, ao mesmo tempo em que "redivive" o projeto de Mallarmé de incorporar nas Letras a anatomia da música, elegendo o ritmo (e não a progressão lógica) como princípio organizador da coletânea.

Palavras-chave: ritmo; fantasia (música); Stéphane Mallarmé (1842-1898); Eduardo Guimaraens (1892-1928).

Há pouco mais de um século, em 1916, o poeta gaúcho Eduardo Guimaraens (1892-1928) publicava no Rio de Janeiro o livro Divina Quimera, cujo título estabelecia um diálogo inequívoco com a obra (e os leitores) de Dante Aligheri (1265-1321) e de Gérard de Nerval (18081855), Les Chimères. As epígrafes, dedicatórias e contínuas alusões a Baudelaire, Poe, Mallarmé - autores de obras de estrutura definida e/ou de textos críticos que as propunham - assim como a divisão em partes estruturadas e a numeração dos poemas evidenciavam a concepção orgânica do livro, já distante da simples recolha de poemas (RICIERI, 2007). Em 1944, Mansueto Bernardi, amigo de Eduardo, edita uma segunda edição, póstuma, a qual acrescenta outros livros sob o mesmo título, altera trechos sem informar o leitor nem explicitar os critérios (gosto pessoal? anotações do poeta?) e desenha um percurso espiritual

Doutora em Teoria e História Literária pela Universidade Estadual de Campinas/ Unicamp, Campinas, São Paulo, Brasil.

E-mail: ellenguilhen2@gmail.com. 
incompatível com a cronologia dos escritos. Na tentativa de compreender o projeto inicial de Eduardo, tomaremos a edição de 1916, por ele cuidadosamente elaborada, como referência.

"Prelúdio", o poema de abertura, estabelece uma leitura musical que se confirma numa série de procedimentos (aliterações, assonâncias, repetições de palavras e de versos, de imagens e formas fixas), de menções a compositores (Chopin, Schumann), voz e instrumentos (piano, violino, harpa, sino), formas e nomenclatura musicais (sonata, noturno, adágio, scherzo), entre outros recursos, que se acumulam ao longo do livro. Longe de ser decorativa, ilustrativa, comparativa, sugestiva ou apenas metafórica, a presença da música em Divina Quimera é de ordem estrutural, alinhada às proposições de Mallarmé de que "não eram as imitações dos sons musiciais que seriam frutíferas [para a literatura], mas a anatomia, a estrutura do tema e variações, que substituíam a progressão lógica” (BALAKIAN, 2000, p. 70).

Para compreender como Eduardo Guimaraens atualizou o projeto de Mallarmé, iniciaremos este artigo pela análise do poema intitulado "A Stéphane Mallarmé”, presente na Parte II de Divina Quimera. No elogio tecido ao mestre, observaremos que leitura/recorte Eduardo seleciona da obra do poeta francês e quais valores adota para si. Em seguida, recuperando análises estruturais de Flores do Mal, de Baudelaire, e de Poésies, de Mallarmé, traçaremos uma proposta de leitura para Divina Quimera que seria um desdobramento de ambas, um exercício de composição muito peculiar situado entre a progressão temático-narrativa de obras anteriores e a fragmentação que marca o século XX.

\section{O POEMA}

A Parte II de Divina Quimera celebra os mestres, referências para o poeta e seu livro. Dante, Baudelaire, Mallarmé, Nerval, Poe, Chopin marcam presença no livro "enquanto arcabouços teóricos sem os quais esta poética particular não se constitui em si mesma” (RICIERI, 2008, 
p. 3). No entrecruzamento de procedimentos, técnicas e valores de cada uma dessas poéticas, Guimaraens articula a sua voz e estrutura a sua obra.

Apesar do desfile das fontes de inspiração, diálogo e provocação soar bastante heterogêneo - a começar pelos títulos: do Cântico das criaturas de São Francisco de Assis a "Túmulo de Baudelaire" -, podemos vislumbrar uma constante, expressa em maior ou menor grau em cada um dos nove poemas: a tese de que a glória humana é sua angústia, seu grito aos céus. Como repercute o grito de Mallarmé? Ouçamos.

\section{A StÉPhane MaLlarmé}

Do poema 4 da Parte II, conhecemos três versões: a primeira publicada na Revista Fon-Fon! de 12 de outubro de 1912 (quando Eduardo contava com apenas 20 anos), a segunda, bastante modificada, estampada na primeira edição de Divina Quimera, quatro anos depois (os trechos alterados foram marcados em cinza), e a terceira sob a interferência de Mansueto Bernardi, que modifica o verso 8 . Este verso assim se apresenta nas três versões:

$1^{\text {a }}$ (1912) - Seta/ diabólica que, do arco, a tua Mão sustinha?

$2^{a}$ (1916) - seta/ que, ao curvo enigma do arco, a tua mão sustinha?

$3^{\text {a }}$ (1944) - seta/ infernal que num arco, a tua mão sustinha?

O teor da mudança efetuada na $3^{a}$ versão - isto é, um retorno à imagem da $1^{\mathrm{a}}$ - poderia indicar que a sugestão fora proposta por Eduardo em suas anotações no seu exemplar, tendo em vista uma segunda edição de seu livro". As palavras "diabólica" e "infernal" reforçam a ideia de hostilidade à inércia, expressa no verso anterior, o 7. Diante dessas informações, diríamos que a versão de 1944 poderia ser tomada como referência.

Segundo testemunho de Itálico Marcon, Mansueto, seu amigo pessoal, teve contato com o exemplar do poeta, com as anotações deste para uma segunda edição. Durante 45 anos (a partir de 1964), o material de Eduardo, incluindo uma quantidade considerável de inéditos, esteve em posse de Marcon. Tudo se perdeu numa desastradíssima doação de seu acervo ao Banco de Livros da FIERGS, em 2009. 
O estabelecimento de texto se complica quando consultamos o prefácio do próprio Bernardi. Na página 41 ele transcreve o poema tal qual a edição de 1916 (acrescenta apenas uma vírgula após inquieta). $\mathrm{Na}$ página 155, com o verso 8 modificado. Essa dupla apresentação na mesma edição invalida a consideração acima. Assim, a melhor opção é elegermos a versão de 1916, publicada pelo próprio poeta, como a mais confiável.

Transcreveremos as três versões:

Figura 1 - Poema publicado na revista Fon-Fon! em 1912

\section{A Stéphane Mallarmé \\ Ange ou Demon du Ciel ou de l'Enfer, qu'importe? \\ BAUDELAIRE}

De que labio fatal - de Anjo ou Demonio P - vinha toda a doçura extranha, immortal e secreta, que a tua Vóz profunda $\theta$ mysteriosa, ó Poeta ! de um rythmo immemorial e rutilo, continha?

Era acaso a Visão celeste, linha a linha, renascendo atravéz da tua Febre inquieta ou, dos Tempos ferindo a inercia hostil, a Setta diabolica que, do arco, a tua Mão sustinha ?

Mas do Inferno ou do Céo, que importa! E' bella e é tudo: E' bella a Voz ignota, insigne e pensativa que, tragioo e divino, o Azul apavorou!

E é bella a Mão mortal que, a um gesto ideal e mudo, do Sonho ainda por vir a rosa rediviva, tal a de um Semeador magnifico, semeou !

(Do Ouro, do Sangue e do Silencio)

Eduardo Guimaraens

Fonte: Revista Fon-Fon! de 12 de outubro de 1912, ano VI, n. 41, p. 44. 


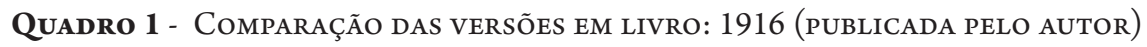
E 1944 (PÓSTUMA)

\begin{tabular}{|c|c|}
\hline Divina Quimera, 1a edição (1916) & A Divina Quimera, 2a edição (1944) \\
\hline A Stéphane Mallarmé & A Stéphane Mallarmé \\
\hline $\begin{array}{l}\text { De que lábio fatal, de anjo ou demônio, vinha } \\
\text { essa harmonia estranha, esplêndida e secreta, } \\
\text { que a tua voz ardente e solitária, Poeta, } \\
\text { como um mistério obscuro e rútilo, continha? }\end{array}$ & $\begin{array}{l}\text { De que lábio fatal, de anjo ou demônio, vinha } \\
\text { essa harmonia estranha, esplêndida e secreta, } \\
\text { que a tua voz ardente e solitária, Poeta, } \\
\text { como um mistério obscuro e rútilo, continha? }\end{array}$ \\
\hline $\begin{array}{l}\text { Era, acaso, a visão celeste, linha a linha, } \\
\text { renascendo, através da tua insônia inquieta } \\
\text { ou, dos tempos ferindo a inércia hostil, a seta } \\
\text { que, ao curvo enigma do arco, a tua mão sustinha? }\end{array}$ & $\begin{array}{l}\text { Era, acaso, a visão celeste, linha a linha, } \\
\text { renascendo, através da tua insônia inquieta } \\
\text { ou, dos tempos ferindo a inércia hostil, a seta } \\
\text { infernal que num arco, a tua mão sustinha? }\end{array}$ \\
\hline $\begin{array}{l}\text { Mas, do inferno ou do céu, que importa? } \\
\text { [É bela: e é tudo! }\end{array}$ & $\begin{array}{l}\text { Mas, do inferno ou do céu, que importa? } \\
\text { [É bela: e é tudo! }\end{array}$ \\
\hline $\begin{array}{l}\text { É bela a voz ignota à boca fugitiva } \\
\text { que, alto, sinistro e eterno, o Azul apavorou! }\end{array}$ & $\begin{array}{l}\text { É bela a voz ignota à boca fugitiva } \\
\text { que, alto, sinistro e eterno, o Azul apavorou! }\end{array}$ \\
\hline $\begin{array}{l}\text { E é bela a mão febril que, a um gesto lento e mudo, } \\
\text { do sonho ainda por vir a rosa rediviva }{ }^{2} \\
\text { - tal a de um semeador magnífico - semeou! }\end{array}$ & $\begin{array}{l}\text { E é bela a mão febril que, a um gesto lento e mudo } \\
\text { do sonho ainda por vir a rosa rediviva } \\
\text { - tal a de um semeador magnífico - semeou! }\end{array}$ \\
\hline
\end{tabular}

Fonte: Elaborado pela autora (2017).

Qual é a fonte do seu canto? De onde brota essa voz tão diferente, tão única? Pertence a um anjo ou a um demônio? O que possuía ("continha”, "sustinha") ou pelo que era possuída (vinha a visão celeste linha a linha)? As perguntas dos quartetos insistem no desejo de entender a origem do canto, compreendida como crucial para o poeta francês. São elaboradas, entretanto, em termos baudelairianos - celestial ou diabólica?

Para Mallarmé, a obra literária é conquista pessoal de cada artista (RICIERI, 2007, p. 119): “Toda alma é uma melodia, que se trata de reatar; e para isso, são a flauta ou a viola de cada um" (MALLARMÉ, 2010, p. 161). De acordo com poema de Eduardo, a escuta/o desenvolvimento

\footnotetext{
2 A segunda versão, de 1916, exclui a vírgula aqui.

3 A terceira versão, de 1944, suprime a vírgula após "mudo”.
} 
dessa voz seria possível no isolamento, num trabalho secreto e solitário, "lento e mudo" (v. 12). Somente assim seria possível produzir o resultado ("seta infernal") que fosse capaz de atravessar a "inércia hostil" da repetição e dos padrões.

Recorrendo aos escritos de Mallarmé, concluímos que a formulação acima transcrita é mais profunda do que pode parecer a princípio. Ora, depois de excluir de sua poesia os assuntos habituais, Mallarmé-poeta exclui a si mesmo:

A obra pura implica a desaparição elocutória do poeta, que cede a iniciativa às palavras, pelo choque de sua desigualdade mobilizadas; elas se iluminam de reflexos recíprocos como um virtual rastro de fogos sobre pedrarias, substituindo a respiração perceptível no antigo sopro lírico ou a direção pessoal entusiasta da frase. (MALLARMÉ, 2010, p. 164)

Sem objeto, sem sujeito, o que resta? Afinal, quem fala num poema? Mallarmé desejava que fosse a linguagem ela mesma, uma linguagem sem enunciador.

le poème rendu à lui-même et privé de tout autre sujet, ne pouvait que se donner lui-même comme sujet: sous les déguisements de la surface, sous "la vaine couche suffisante d'intelligibilité" "concédée à la retine", il ne fait que montrer sa propre genèse sous l'impulsion du rythme qui le fait être. (DELÈGUE, 2001, p. 1429) ${ }^{4}$

Reduzida a si mesma, a poesia só poderia dizer da irredutível e misteriosa necessidade que lhe dava existência: o impulso rítmico. No artigo "Mallarmé, le sujet de la poésie", Yves Delègue desenvolve a discussão sobre o sujeito dessa poesia. À pergunta proposta por Pascal - o que é o eu? - Mallarmé responde:

4 o poema feito para si mesmo e privado de qualquer outro assunto, só poderia se dar a si mesmo como assunto: sob os disfarces da superfície, sob "a vã camada suficiente de inteligibilidade" "concedida à retina", ele apenas mostra a sua própria gênese sob a impulsão do ritmo que o faz ser/existir. (Tradução da autora). Os trechos entre aspas na citação são de "O mistério nas letras" (MALLARMÉ, 2010, p. 186) 
Toute âme est un nœud rythmique”, dit-il, l'âme, c'est-à-dire ce qui, au sens propre, anime le vivant, ou encore le "creux néant musicien" dans lequel se rencontrent et se nouent les pulsations, les pulsions de l'être. Mystérieusement "élu", le poète a le privilège ou la fatalité de les faire sonner dans le langage. (DELÈGUE, 2001, p. 1429)5

O poeta é aquele que cede/segue o "instinto de ritmo que o elege", como dito em "O mistério nas letras". Isto é, uma força em latência (pulsão, pulsação) que dá sentido às formas do mundo. Esse sentido não é alcançado por antigas tipologias da retórica e do estilo, mas pelos cortes vitais de uma lógica com as nossas fibras. Os cortes, como relâmpagos, iluminam a totalidade; o fragmento evoca o poema absoluto, presente por sua negação:

Moi, l'humble, qu'une logique éternelle asservit”, dit-il, une logique "avec nos fibres", dont les "primitives foudres" disjoignent inlassablement les éléments de la totalité pour leur permettre de se recomposer en raison des "coupes vitales" qui scandent la marche de l'être. (DELÈGUE, 2001, p. 1431) ${ }^{6}$

Essa grande liberdade adquirida não é a licença de escrever não importa o quê. $\mathrm{O}$ fato de não ser codificada de início não torna a exigência rítmica menos estrita, mas indica que ela obedece a uma lógica diferente da cartesiana (que seleciona a matéria tendo em vista seus fins) ou da dialética retórica (que encadeia o conteúdo visando a eloquência e o encantamento).

5 Toda alma é um nó rítmico", ele diz, entendendo a alma como aquilo que, literalmente, anima a vida, ou ainda o "nada e oco músico" no qual se encontram e se enlaçam as pulsações, as pulsões do ser. Misteriosamente "escolhido", o poeta tem o privilégio ou a inevitabilidade de fazê-los [pulsões e pulsações] soar na linguagem. (Tradução nossa). O trecho citado é de "A música e as letras".

6 O Eu, o humilde escravo de uma lógica eterna", de uma lógica "com as nossas fibras", dos quais os "primitivos relâmpagos" desunem incansavelmente os elementos da totalidade para lhes permitir se recomporem em razão de "cortes vitais" que escandem a marcha do ser. (Tradução nossa). 
Voltemos ao poema de Guimaraens. Depois de discutir a fonte (estrofe 1) e o controle do poetar (estrofe 2) - celestial linha a linha ou curvo enigma diabólico? - o eu lírico altera a questão: "Mas, do inferno ou do céu, que importa? É bela: e é tudo!” (v. 9). Mais do que desvendar o mistério, cabe usufruir sua beleza, e tudo estará contido nesse deslumbre.

Continua: "É bela a voz ignota à boca fugitiva". A voz, pois, que combina esplendor e mistério, obscuridade e iluminação (rútilo significa ouro muito vivo), em "doçura" (1 ${ }^{\text {a }}$ versão) ou "harmonia" estranha (singular, desconhecida, absurda ao senso comum), escapa aos lábios, é desconhecida, exatamente como na obra pura preconizada por Mallarmé. Sua origem não pode ser estabelecida.

No seu prefácio a Estrutura da lírica moderna (2007), Alfonso Berardinelli questiona na leitura de Friedrich, centrada em Mallarmé, a análise de procedimentos estilísticos dissociada do conjunto da obra de cada autor e a não relação das transformações formais da poesia com a autoconsciência histórico-cultural dos autores. Incomoda-o o descolamento sócio temporal dessa "poesia [que] se apresenta em seu conjunto como uma criação sem sujeito, uma obra sem autores".

No entanto, o debate em torno da origem do canto e do estabelecimento do ritmo não indica que esta poesia - ao se apresentar "como um sonho ou um labirinto dentro do qual os autores aprenderam a morar e de onde não poderiam sair” (BERARDINELLI, 2007, p. 21) não participa dos questionamentos fulcrais da virada de século. Há uma tensão insolúvel no centro dessa lírica, inerente à condição humana ${ }^{7}$ mas também alinhada a profundas mudanças experimentadas no seu tempo.

Se a partir de Nerval ("Cristo nas Oliveiras"), o Absoluto - que garantia o significado do ritmo na natureza - já não pode mais ser invocado (EVANS, 2004, p. 12), como manter/crer numa ordem? David Evans, em

Simona Pollicino (2011, p. 36) nos lembra que a questão remonta aos gregos. Para Platão, o ritmo é da ordem do movimento, encarnação da ideia fundadora de uma ordem cósmica. Para Aristóteles, por outro lado, não se trata de uma manifestação do Absoluto, mas seu oposto: o ritmo seria a representação da possibilidade de ação humana. 
Rhythm, Illusion and the Poetic Idea: Baudelaire, Rimbaud, Mallarmé, coloca a questão nesses termos:

in a world without the universal analogy there remains an irresolvable question as to the nature of this order, a question exploited by Mallarmé throughout his later career: is rhythm imposed or discovered? Do we arrange l'informe into la forme, or are we really the sensitive observers of an underlying meaning which pre-exists our gaze? It is precisely this interpretative instability that the post-illusory poetry of Baudelaire, Rimbaud and Mallarmé obliges us to confront, recreating in the drama of form the irresolvable tension of the human condition, like the inescapable 'peut-être' of the Mallarméan constellation (EVANS, 2004, p. 311-312). ${ }^{8}$

A fonte que estabelece o(s) ritmo(s) é, portanto, uma questão central para o período e para a poética de Mallarmé, e Eduardo optou por contemplá-la no soneto.

Ainda em torno do estabelecimento de texto, notemos que a versão de 1912 contém termos e imagens muito expressivas, extremas. Na versão de 1916, a substituição de "ritmo imemorial" por "mistério obscuro" (v. 4), "Febre" por "insônia" (v. 6), "seta diabólica” por "curvo enigma do arco" (v. 8), "trágico e divino" por "alto, sinistro e eterno" (v. 11), "mão mortal” por "mão febril" (v. 12), "gesto ideal e mudo" por "gesto lento e mudo" (v. 11) parece diluir a dramaticidade, internalizando o processo. Observemos, sobretudo, que a troca de "ideal" por "lento" e "febre" por "insônia" trazem para dentro do eu lírico a expressão de grandeza e a agitação externalizadas

8 em um mundo sem a analogia universal, permanece uma questão insolúvel quanto à natureza dessa ordem [que constitui a poesia], uma questão explorada por Mallarmé ao longo de sua carreira posterior: o ritmo é imposto ou descoberto? Organizamos o informe em forma, ou somos realmente os observadores sensíveis de um significado subjacente que preexiste ao nosso olhar? É precisamente essa instabilidade interpretativa que a poesia pós-ilusória de Baudelaire, Rimbaud e Mallarmé nos obriga a confrontar, recriando no drama da forma a tensão irresolúvel da condição humana, como o inevitável "peut-être" da constelação mallarmeana. (Tradução nossa). 
na primeira versão. Esse processo de internalização alinha-se ao pedido, feito no poema "Dante", também presente na Parte II:

Dante! - Quero-o, porém, mais doloroso e terno, mais humano, a compor, torturado e feliz, sob a angústia mortal do seu secreto inferno, uma canção de amor em louvor de Beatriz! (GUIMARAENS, 1916, p. 48)

Um canto que brotasse do "secreto" inferno, escondido sob a angústia mortal, representaria um apagamento exterior do turbilhão e da paixão e, ao mesmo tempo, ao torná-lo íntimo, uma intensificação. Suprimir para destacar. Trata-se de um movimento semelhante ao apagamento do material que impulsionou a escrita que Friedrich descreve em Mallarmé ao analisar sucessivas versões de seus poemas.

Curiosamente, na acepção musical, o vocábulo "destacar" carrega a ideia de corte: o dicionário o define como a articulação de notas sucessivas, separando-as como se fossem cortadas por pequenas pausas. Além de ampliar a força e a tensão, o corte seria fundamental no estabelecimento do ritmo, lembra-nos Kiefer (1979, p. 23) em Elementos da linguagem musical:

Se pensarmos no fluir tranquilo e contínuo de uma corrente de água ou na emissão contínua de um som no qual nada se altere, não teremos a noção de ritmo. Falamos em ritmo a partir do momento em que o fluir apresenta descontinuidades.

Como entender, porém, a mudança de "ritmo imemorial" para "mistério obscuro"? Evidentemente ambos se referem à mesma ideia, no entanto, o termo "ritmo" é ainda mais revelador das propostas poéticas de Mallarmé. Por outro lado, a construção frasal da primeira estrofe na primeira versão não flui adequadamente, deixando o verso 4 solto. Para não precisar modificar os três versos iniciais, caberia apenas uma comparação nessa posição. Assim, nossa hipótese é de que a substituição se deu - 
ironicamente - por questões de ordem rítmica: a menção a "ritmo" foi excluída para que a estrofe ganhasse ritmo.

Eduardo Guimaraens era um cultor do ritmo. Tradutor, fez questão de assinalar em Dante Canto Quinto que o ritmo era o principal critério a guiar sua transposição. No prefácio aos 83 poemas de Flores do mal que traduziu, ele também justifica o seu critério:

Idéias e imagens, concepção e forma, o hábil metrificador, com maior ou menor exatidão, sempre que se esforce muito e muito, poderá passavelmente reproduzir. Mas, em poesia, como em certa prosa artística, existe sempre um ritmo secreto, uma oculta harmonia, a música de cada voz, um timbre especial e peculiar. (GUIMARAENS, 1944, p. $93)^{9}$

"Um ritmo secreto, uma oculta harmonia, a música de cada voz, um timbre especial e peculiar" que Eduardo procura captar e transpor se aproxima bastante da citação de Mallarmé que inicia esta análise: "toda alma é uma melodia, que se trata de reatar". "Essência divina" da poesia, "em parte sua razão de ser" ${ }^{10}$, o ritmo - imemorial e rútilo - semeia nova epifania do amor de um Sonho ainda por vir e permite (de acordo com a $1^{\text {a }}$ versão, de Fon-Fon!) que o semeador mortal Mallarmé cultive a rosa sempre-viva, humano gerando eterno.

Posto o ritmo como ponto de encontro dessas duas poéticas, acompanhemos seu papel na organização das coletâneas. Antes, porém, resgataremos uma análise que questiona a leitura narrativo-linear de Flores do mal: sob esta proposta, o livro de Baudelaire - ao manter a direção em

9 O prefácio às traduções foi publicado na íntegra por Mansueto Bernardi no estudo da edição de 1944: páginas 91 a 95. Infelizmente, devido à perda irrecuperável, não temos acesso a maior parte das 83 traduções mais musicais do poeta francês.

10 As expressões são do texto "Sobre o que são os poetas modernos", escrito por Eduardo para o Correio do Povo e publicado por esse jornal em Porto Alegre em 8 de outubro de 1925, página 3. Uma transcrição desta coluna pode ser encontrada em BERWANGER DA SILVA, Maria Luiza. Paisagens Reinventadas: Traços Franceses no Simbolismo Sul-Riograndense. Porto Alegre: Ed. Universidade/UFRGS, 1999. p. 300- 301. 
suspenso - guardaria semelhanças com a organização rítmica de Poésies e Divina Quimera e também se situaria na transição entre a crença na arte como reflexo do cosmos criado e a fragmentação do homem moderno, constantemente em dúvida.

\section{O LIVRo}

BAUdelaire E A ESTRUTURA DiALÉTICA DE FLORES DO MAL

A primeira edição de Flores do Mal data de 1857 e era composta por 101 poemas: o primeiro, separado do conjunto principal e sem número, intitulava-se "Ao leitor". Os 100 poemas numerados distribuíam-se em cinco partes da seguinte forma: "Spleen e ideal" (77 poemas), "Flores do mal" (12), "Revolta” (3), "O vinho" (5), "A morte" (3), indicando que o livro de poemas propunha um percurso de leitura. ${ }^{11}$

Acusado de ultrajar a moral pública e judicialmente obrigado a retirar seis poemas, Baudelaire publicou, em 1861, uma segunda edição do livro contendo 35 poemas novos, 126 ao todo. O pedido feito pelo poeta a Alfred de Vigny de que o livro não fosse visto como um simples álbum estimulou uma série de estudos em torno da unidade e da sequência de Flores do mal.

De 1861 em diante várias foram as tentativas dos críticos de explicitar qual seria a arquitetura "secreta" do livro. Em Alexandre Ourosoff (1896), L.-F. Benedetto (1912), Marcel Ruff, Albert Feuillerat, Jacques Crépet, Georges Blin, Lloyd James Austin, D. J. Mossop, as cinco sessões da edição de 1857 e as seis da edição de 1861 são descritas como

11 Para uma análise da estrutura da $1^{\text {a }}$ edição, indicamos: "O convite à viagem. Notas sobre o exótico nas Flores do mal. [Breve especulação sobre a estrutura da primeira edição das Flores do mal]”. Disponível em: <http://paulofranchetti.blogspot. com.br/2012/07/notas-de-leitura-das-flores-do-mal-de.html>. Acesso em: $10 \mathrm{abr}$. 2019. 
uma progressão do nascimento à morte e como dicotomias do spleen e do ideal em direção ao abismo niilista.

Em 1997 James R. Lawler propôs uma leitura diferente. Para ele, Baudelaire aderira a uma epistemologia da dualidade que comandaria os mundos material e espiritual e que ele procurou meticulosamente respeitar na composição de seu livro. No artigo The Poet and the Chimcera: Duality in Baudelaire's "La Mort", ele resume:

Baudelaire's dialectic reveals the chimæra: the twin faces of transcendence and immanence tell of desire unquenchable. The collection becomes the mise en forme of a duality traced in the sequence of its tragic conflicts with unwavering purpose. (LAWLER, 1991, p. 19) ${ }^{12}$

Harmonia é a combinação de sons simultâneos, melodia é a combinação de sons sucessivos. Em Baudelaire, diríamos que a tensão se manifesta e se sustenta tanto no plano harmônico - elevado e rebaixado soando simultaneamente - quanto no plano melódico - um poema respondendo a outro, numa espécie de equilíbrio ambivalente.

A articulação de um assunto em metades complementares de uma dualidade se evidencia nesta análise de Lawler sobre o tema da morte nos poemas finais de Flores do mal:

Baudelaire's genius for composition brings together the six poems of "La Mort" in two symmetrical clusters. Death first appears as lyrical harmony in the likeness of perfect love ("La Mort des amants"), then religious hope and faith ("La Mort des pauvres"), then pathetic redemption ("La Mort des artistes"): the movement pricks the bubble of confidence while maintaining the image of a possible post mortem consolation. On the other hand, in the last three poems, an antithetical attitude is taken as death appears in the form of a voluptuous mistress ("La Fin d'une journée"), an empty stage ("Le Rêve d'un curieux"), an

12 A dialética de Baudelaire revela a quimera: as duas faces da transcendência e da imanência falam do desejo inextinguível. A coletânea se torna a mise en forme de uma dualidade traçada na sequência de seus trágicos conflitos com imutáveis/inabaláveis/imóveis propósitos. (Tradução nossa). 
ocean-crossing ("Le Voyage"). The second group responds to the first by a progression that entails erotic pleasure, thwarted desire, metaphysical passion as the poet, like a canonist, discriminates one attitude from another. The use of two groups, however, breaks the spell that would allow a single penchant to impose itself since thought assumes its extremes. (LAWLER, 1991, p. 18-19) ${ }^{13}$

James R. Lawler questiona, portanto, a interpretação de sentido ascendente ou descendente de Flores do mal, mostrando que, ao contrabalançar os dois lados opostos na disposição dos poemas e colocar a questão moral em forma de argumento dramático, Baudelaire impede que uma única propensão se imponha. Numa atualização da cosmovisão pitagórica - toda coisa nasce de dois fatores opostos (NIETZSCHE, 1999, p. 63), Baudelaire proporia um equilíbrio ambivalente que transformaria a própria tensão em eixo estruturante de sua coletânea.

Diferentemente do que defende o senso comum, tensão e harmonia não são excludentes. A própria definição de harmonia - disposição equilibrada e justa entre as partes de um todo - pressupõe impulsos que serão sopesados por outros de igual força e/ou expressão. Vejamos, pois, como este equilíbrio móvel se desenha em Mallarmé.

\section{Mallarmé e a Configuração Rítmica de PoÉSIES}

Em La mise en scène de la Fiction: réflexions autour de la structure du recueil des Poésies de Mallarmé (2001), François Châtelain argumenta que

13 O genial talento de Baudelaire para a composição reúne os seis poemas de "La Mort" em dois clusters simétricos. A morte aparece pela primeira vez como harmonia lírica à semelhança do amor perfeito ("La Mort des amants"), depois como esperança e fé religiosas ("La Mort des pauvres"), então como redenção patética ("La Mort des artistes"): o movimento espeta a bolha de confiança enquanto mantém a imagem de uma possível consolação pós-mortem. Por outro lado, nos últimos três poemas, uma atitude antitética é tomada à medida em a morte aparece sob a forma de uma amante voluptuosa ("La Fin d'une joumee"), um palco vazio ("Le Reve d'un curieux"), uma travessia oceânica ("Le Voyage"). O segundo grupo responde ao primeiro por uma progressão que implica prazeres eróticos, desejo frustrado, paixão metafísica quando o poeta, como um conhecedor do cânone, diferencia uma atitude de outra. O uso de dois grupos, no entanto, quebra o feitiço que permitiria que uma única propensão se impusesse, uma vez que o pensamento assume seus extremos. (Tradução nossa). 
a dispositio nesta coletânea poética de Mallarmé é de natureza mais rítmica do que discursiva. Deve ser medida pelo jogo de equilíbrio e desequilíbrio, pontos e contrapontos, sempre considerando que, para o poeta, silêncio e som, o branco e a escrita, são poeticamente indissociáveis.

A alternância de poemas marginais com grandes sonetos ou de poemas longos e poemas curtos ou mesmo a designação de certas peças como simplesmente intercalares poderia ser lida, portanto, como uma resposta a exigências de ordem rítmica. A alternância seria, para o poeta, fundamental para a manutenção do interesse/da atenção. Na enquete a Jules Huret, Mallarmé diz: "On entend tout d'un coup dans les orchestres de très beaux éclats de cuivre; mais on sent très bien que s'il n'y avait que cela, on s'en fatiguerait vite" ${ }^{14}$. Proposição semelhante encontramos em $O$ livro, instrumento espiritual, publicado em Divagações:

Por que - um jato de grandeza, de pensamento, ou de emoção, considerável, frase prosseguida, em grande caractere, uma linha por página na posição graduada, não manteria o leitor em alerta, a duração do livro, com apelo a seu poder [potência] de entusiasmo? ao redor, miúdos, grupos, secundariamente de acordo com sua importância, explicativos ou derivados - uma semeadura de floreios. (MALLARMÉ, 2010, p.184)

Poderíamos entender que a sonoridade menor exaltará a sinfonia, o clarão podendo estar em qualquer poema. No mesmo texto, Mallarmé adverte: "A Poesia, próxima a ideia, é Música, por excelência - não consente inferioridade" (2010, p. 183). Como jogo cujos elementos adquirem valor na oposição, no sistema, sem subordinação ou hierarquia, a poesia tal como a música se constituiria como um discurso puramente virtual.

$\mathrm{Na}$ linguagem da música, movimentos são partes de uma composição, divididas por diferença de ritmo, andamento ou mesmo de tonalidade. A escuta parcial de uma peça - apenas um movimento ou trecho - não é capaz de dar conta das relações que este estabelece

14 De repente ouvimos nas orquestras belos estilhaços de cobre; mas nos sentimos muito bem que, se não houver nada além disso, nos cansaremos rapidamente. (Tradução nossa) 
com o todo. Há uma organicidade, um todo que visa à solidificação e ao equilíbrio de uma ideia musical e que revela a consistência temática da peça. A apreciação completa desse conjunto possibilitaria a experiência da catarse proposta pelo compositor, que é interrompida ou enviesada no recorte.

Mesmo que os discursos tradicionais de ordem do mundo e ordem do discurso tenham sido deslegitimados, e que, na poética de Mallarmé, a catarse não seja mais uma aspiração possível, a mobilização de um sistema pelo ritmo entre as relações seria, em sua visão, algo divina (pelo menos no sentido de poeisis: criação, arte de fazer, dar à luz algo que não existia):

les relations à distance qu'il [le recueil] instaure, les réfractions complexes qu'il permet, les jeux d'échos, en font déjà un système très mobile, une "Musique dans le sens grec, au fond signifiant Idée ou rythme entre des rapports; là, plus divine que dans son expression publique ou symphonique"; l'introduction visible de séries, de regroupements variables à partir de "Don du poème" a aussi, semble-t-il, pour but de rendre perceptible au lecteur cette configuration rythmique du recueil, comme déjà le double encadrement par le blanc qui projette sur le recueil la configuration rythmique de tout poème. (CHÂTELAIN, 2001, p. 102) $)^{15}$

Tornar perceptível ao leitor a configuração rítmica da coletânea pelo ritmo estabelecido entre relações e pela introdução visível de séries - eis a meta. Em Crise de verso, Mallarmé a anuncia, em outras palavras:

Estamos lá, precisamente, a procurar, diante de uma quebra dos grandes ritmos literários [...] e seu espalhamento em frêmitos articulados

15 as relações à distância que ela instaura, as refrações complexas que ela permite, os jogos de ecos, constituem já um sistema muito móvel, uma "Música no sentido grego, no fundo significando Ideia ou ritmo entre as relações; nisso mais divina que na sua expressão pública ou sinfônica"; a introdução visível de séries, de reagrupamentos variáveis a partir do "Dom do poema" tem também, ao que parece, a intenção de tornar perceptível ao leitor essa configuração rítmica do conjunto, como já o duplo enquadramento do branco que projeta sobre a coletânea a configuração rítmica de cada poema. (Tradução nossa) 
próximos da instrumentação, uma arte de finalizar a transposição, ao Livro, da sinfonia. (MALLARMÉ, 2010, p. 166)

Para transpor uma sinfonia em Livro, seria preciso que as palavras se portassem como centro de suspense vibratório, capazes de sugerir mais de um nível de imagens. Devem soar não na sequência ordinária, antes como "reciprocidade de fogos":

- As palavras, por si mesmas, se exaltam em muita faceta reconhecida a mais rara ou valente para o espírito, centro de suspense vibratório; que as percebe independentemente da sequência ordinária, projetadas, em paredes de grota, enquanto dura sua mobilidade ou princípio, sendo o que não se diz do discurso: prontas todas, antes da extinção, a uma reciprocidade de fogos distante ou apresentada de viés como contingência. (MALLARMÉ, 2010, p. 189)

As metáforas de fogos, relâmpagos e pedras dinamitadas reaparecem com frequência nas Divagações de Mallarmé para descrever essa forma de composição mobilizada pelas palavras. $\mathrm{O}$ conhecido verso de "A tumba de Edgar Poe" - "calmo bloco caído de um desastre obscuro" - meteorito gerado pela explosão de um astro desconhecido, sem origem, sem fim, se presta, na leitura de Yves Delègue em "Mallarmé, le sujet de la poésie”, como a síntese da obra ideal para o poeta.

Ainda em Crise de verso, Mallarmé (2010, p. 163) aproxima o meteoro da sinfonia: "O moderno dos meteoros, a sinfonia, ao sabor ou à revelia do músico, aproxima o pensamento; que não se vale mais somente da expressão corrente”. Mantendo a imagem dos relâmpagos, a mobilização, produzida pelo choque, pela projeção e pelo suspense vibratório das palavras, possibilitaria que elas se iluminassem "de reflexos recíprocos" (p. 164).

"Para que haja entre as palavras uma corrente alternada de simpatia, umas devem refletir as outras", nos lembra Zélia de Almeida Cardoso no artigo A teoria poética de Mallarmé (1976, p. 416). Ela continua:

Cada palavra seria uma espécie de pedra preciosa, capaz de receber e propagar o mais leve raio de luz, mas, ao mesmo tempo, essas palavras- 
-espelho devem estar separadas, porque distantes umas das outras elas se desdobrarão. Daí a necessidade de elementos de ruptura, de elipse, de fragmentação, que irão preparar a recriação de uma unidade ulterior. A descontinuidade será utilizada como meio de reconciliação; a atomização da linguagem será um meio para reuni-la e fundi-la em si mesma. $\mathrm{O}$ sentido nasce de um efeito de ressonância; o verso funciona como uma gruta ou um alaúde. (CARDOSO, 1976, p. 416)

Se em Baudelaire conseguimos visualizar ainda uma divisão em blocos temáticos que narrativamente se sucedem (mesmo que o sentido dessa narrativa esteja sempre em suspensão, em tensão), Mallarmé propõe aqui espalhar/espelhar as ressonâncias. Serão elas que, soando nesse jogo de ecos, "reciprocidade de fogos", produzirão uma recriação da unidade, harmônica sinfonia, acendendo um novo sentido poético. "Os abruptos, altos jogos de asa, se mirarão, também: quem os conduz percebe uma extraordinária apropriação da estrutura, límpida, aos primitivos raios da lógica”, Mallarmé garante (2010, p. 189).

Como um móbile, teremos uma arquitetura de relações espelhantes e de ecos, que se organizam a partir de exigências de ordem rítmica (alternâncias, repetições, prolongamentos, sínteses, silêncios, entre outras). Retomando a definição de música como ideia ou ritmo entre as relações, concluímos que ela só será "escutada” no conjunto. No entanto, como se trata de relâmpagos, fogos, centro de suspense vibratório, lampejos, pedaços de meteoros, o contato é bastante efêmero e logo se apaga: permite entrever o mistério, sem desvendar o enigma. Divina (e breve) quimera.

\section{Eduardo e A ORganicidade MUSICAl de Divina QUimera}

Traçar o percurso narrativo de um livro cujo título dialoga de modo tão explícito com Divina Comédia, e cuja apresentação se dá em partes numeradas, será uma tentação (obrigação?) inescapável aos críticos que descreveram a obra. 
Comecemos pelo verbete de Ana Maria Lisboa de Mello em Pequeno Dicionário da Literatura do Rio Grande do Sul: em sua descrição, a obra trata do eu lírico em busca do ser amado, busca marcada pelo sofrimento da espera angustiante, da dúvida e da melancolia, mas que termina em encontro. A leitura da Parte II como tormento compensado pelo amor sentido pelo eu lírico é bastante forçada. A escolha dos versos finais do poema 13 da Parte V (o que antecede "Final") para ilustrar o final do percurso, aproximando o sofrimento passado da felicidade, também será realizada por Maria da Glória Bordini.

Para Lígia Averbuck, no prefácio à terceira edição (1978) no qual mistura avaliações à Divina Quimera de Eduardo (1916) e A Divina Quimera de Mansueto Bernardi (1944), o livro "refaz o caminho de um ser frágil em busca do amor e de si próprio”. (AVERBUCK, 1978, p. 16). A tortura do eu lírico se daria por conta da dualidade matéria e espírito, influência de Baudelaire. O poeta "só se permitirá as alegrias do sonho" ( $\mathrm{p}$. 15), completa.

Bordini (1980), por sua vez, elegerá o amor desenganado como tema geral do livro, à exceção da Parte II. Tendo se visto inicialmente estimulado, o amor do eu lírico teria sido depois confundido pela impassibilidade da amada. Ele sofre sua indiferença por longo tempo e se alimenta de recordações de desejos irrealizados até que "finalmente atinge de novo a Amada e se apresta para as núpcias” (p.76).

Nessa exposição, a Parte II, que poderia parecer supérflua, funcionaria como um "interlúdio musical entre a Parte I, que coloca o tema da indiferença e da dor, e a Parte III, que desenvolve o da distância e da saudade" (1980, p. 76).

Como veremos, o livro está construído em nuances e oscilações, de modo que a distância e saudade assim como "estranha voz" sem corpo, que Bordini verá como uma inovação da Parte III, já estavam presentes na Parte I. Concordamos, entretanto, que o tema do sofrimento associado à amada ganha tons mais intensos na Parte I do que na Parte III: "a dor do amor irrealizado punge menos com o tempo e está transformada em melancolia, com menos queixas e maior resignação", defende (p. 78). 
Essa oscilação entre as Partes I, II e III está presente no interior da Parte I. Observemos a análise rítmica que Bordini realiza dessa primeira seção:

Há, pois, um entrelaçamento de ritmos breves e longos, dançáveis ou pensativos, que acentua a ambiguidade antes mencionada no plano semânticos [ora a idealização da mulher como Virgem inacessível, ora a imaginação de que a Amada lhe corresponde o amor, mas mantém essa atitude em silêncio]. Na verdade, tanto nas sonoridades como nas significações, o Poeta oscila entre a dor consentida e o prazer sonhado. (BORDINI, 1980, p. 78)

Entre os ritmos longos, pensativos e mais intimistas, algo sussurrado, destacaríamos os poemas 3, 5 e 9. Entre os breves, dialogados ou dançáveis, citamos os poemas 2, 4 e 13. Bordini (1980) associa o ritmo dos dísticos, tercetos e quadras ao cantábile, termo musical que significa cantável ou como uma canção. Na música instrumental, indica um particular estilo de tocar imitando a voz humana. Para compositores posteriores ao século XVIII, sobretudo os de piano, o termo indica a ênfase de uma linha musical em particular, diferindo do contraponto que desenvolve direções melódicas simultâneas. Nesta parte, o cantábile - marcado pelo sofrimento e pelo lamento dolorido - poderia ser encontrado em "Se a vida é bela, ardente e forte [...]/ por que sem causa adoro a morte” (poema 1), "Olvidada tortura, hora esquecida" (poema 13), "Sofrer! Sofrer, e após? Sofre-se como se ama” (poema 15). Alguns poemas parecem se definir pela mistura de vozes chorando e pelo sussurro doce, como em "Dói-me a recordação de ti, como de um sonho”, que se inicia com um refrão (verso que também finaliza o poema), e aos poucos adquire um tom ainda mais "grave e lento/ como sobre o teclado abafado e soturno/ de um órgão" onde, sobre um piano, "agoniza um noturno" (v. 10).

Por meio de uma ode e oito sonetos mais atormentados, o interlúdio da Parte II quebraria o ritmo lamentoso da Parte I. Conjunto encaixado em outro conjunto (o livro), a Parte II funcionaria como um "espelho metalinguístico dentro de um discurso poético que o reflete 
e o faz reconhecer-se" (BORDINI, 1980, p. 76). O termo "espelho" poderia levar à falsa conclusão de que a parte atuaria como um resumo do restante. Quanto ao tom e os temas isso não é verdadeiro, mas é nela que encontramos "as bases estéticas, filosóficas e eruditas para o poema inteiro ${ }^{16 ”}$ (p. 76).

A Parte III retoma a atmosfera mais fluida da Parte I. A oscilação entre poemas longos $(1,3,5$ e 7$)$ e poemas curtos $(2,4)$, evidente nesta parte, contribui para interesse da leitura. Se todos têm o mesmo ponto de partida, o mesmo tom melancólico, as mesmas imagens do circunscrito, a alternância de extensão dita o ritmo e garante que o leitor/ouvinte não se aborreça ${ }^{17}$. Quanto ao tema,

A distância da Amada, real ou virtual, consente no sonho mais ousado: o Poeta confessa seu "desejo alucinante" e permite-se o luxo de imaginar a mulher amada soluçante, dolorida, pronta para recebê-lo sorrindo se uma reaproximação for tentada. Cresce uma expectativa hesitante, feita de recuos da parte do Poeta, marcada pelo ritmo stacatto das quadras, que nessa Parte são a forma estrófica mais utilizada. (BORDINI, 1980, p. 78)

A Parte IV está escrita em forma-sonata, uma forma musical fixa, em conformidade com título "Sonata sentimental”. A estrofação em dísticos - que sugere o movimento compassado da dança, tal como a lânguida pavana mencionada no poema. Bordini (1980, p. 80) a elege como a parte menos atribulada e menos sublimada de toda obra, já que o eu lírico "se atreve ao beijo e esquece o respeitoso distanciamento de 'irmão' das partes anteriores".

A Parte V, composta por dois poemas em decassílabos (2 e 11), oito em dodecassílabos, um em redondilha menor (12) e dois alternando versos

16 Bordini (1980) reproduz aqui a leitura de Mansueto Bernardi que propõe Divina Quimera como o mais longo poema de amor da literatura brasileira (Cf. BORDINI, 1980, p. 74). Na página 76 de seu artigo ela classificará Divina Quimera como uma longa elegia.

17 Os metros dos poemas seguem esta ordem: 1. decassílabo, 2.verso livre, 3. dodecassílabo, 4. decassílabo, 5. verso livre, 6. decassílabo, 7. octossílabo. 
de 12 e 8 sílabas, apresenta poemas de estrofação mais extensa e irregular envolvidos por uma balada (poema 2) e um soneto (13). Bordini (1980) associa essas características à indecisão amorosa. Estamos diante de uma sessão bastante fluida, com poemas que lembram e mencionam cartas de amor (poema 4), passeios e datas comemorativas vividos em solidão (poemas 5, 6, 8, 9, 11). Impaciente, o eu lírico adoece de amor e se faz criança (poemas 10 e 12). O soneto final (13) avança, num salto brusco, para as núpcias, concluindo no verso: "Ser feliz, afinal, é ter sofrido assim".

Concluindo o livro, a Parte Final retoma o motivo do lírio claustral (presente em "Prelúdio", poemas 3, 5, 6, 10 da Parte I, 1 e 2 da Parte II, 3 e 6 da Parte III, seção 4 da "Sonata sentimental", 1 e 8 da Parte V), agora colhido e oferecido à Noite.

Bordini (1980, p. 83) encerra seu texto reconhecendo que Guimaraens "mobiliza cada poema como um todo para elaborar uma metáfora complexa, fugidia, bem de acordo com a teoria da sugestão de Mallarmé, que se acrescenta ao conjunto de ambiguidade proposto no tema”. A ambiguidade temática na leitura de Bordini diz respeito à dupla visão do poeta diante da natureza da mulher: virgem inacessível e deusa devoradora, desejada e temida, com quem o eu lírico acaba por encenar uma relação marcada pela repressão e pela sublimação.

Afastando-nos um pouco dessa leitura psicanalítica, nossa proposta de interpretação desloca a ambiguidade para o contexto no qual a relação se desenvolve - o amar na morte - uma atualização da libido melancólica tal como teorizada por Giorgio Agamben em Estâncias: a palavra e o fantasma na cultura Ocidental (2007, p. 45): "a melancolia não seria tanto a reação regressiva diante da perda do objeto de amor, quanto a capacidade fantasmática de fazer aparecer como perdido um objeto inapreensível”.

Essa definição explicaria a relação ambígua e dolorosa que o eu lírico estabelece com sua amada em Divina Quimera. Ele sofre por esse amor, e não sabemos exatamente o porquê. $\mathrm{O}$ encontro no fantástico observado em alguns poemas seria, nas condições em que o eu se encontra, o único contato possível (se entendermos como encontro uma situação tão esvaziada). Isso porque, na desesperada tentativa de se garantir contra sua perda, o eu melancólico tornaria inacessível o objeto. Ele não teria outra 
meta a não ser fazer possível uma apropriação em uma situação em que nenhuma possessão é possível na realidade.

No plano formal, observamos uma clara alternância de caráter: as Partes I, III e V possuem estruturas mais livres, e se assemelham muito entre si quanto à tonalidade e atmosfera que carregam. As Partes II e IV, de formato mais rígido, parecem não dialogar formalmente com as demais, mas não deixam de apresentar motivos comuns ao restante da obra.

Comparemos essa disposição ondulatória com os princípios da forma musical fantasia que Julio Bas (1986) elege como basilares: 1. existência de temas, principais e secundários; 2 . eventual retorno deles no transcurso da peça; 3. delimitação de períodos distintos; 4. contraste de caráter entre eles; 5 . eventual separação das várias partes ou tempos.

Ao fazer uso de notável liberdade de alternância, a fantasia destaca a força dos contrastes, não sendo rara certa brusquidão, como observamos entre as Partes I e II da Divina Quimera: à fluidez da primeira, sucedem-se sonetos mais atormentados, de febril embate espiritual. Com frequência a fantasia emprega o estilo da improvisação, a quem é tributária, sendo comum que partes ou períodos com temas concretos e forma mais fechada sobrevenham a frases, períodos e amplas figurações com caráter indeciso, de transição ou passagem. O movimento inverso (partes indefinidas e mais livres executadas após formas de estrutura mais fixa) também é possível:

a Fantasía debe contener una afirmación tal, que permita satisfacer plenamente el sentido musical; sea que el todo converja hacia el final como una ola que emerge o como una sucesión de aspiraciones siempre ascendentes; sea que, después de alcanzada su máxima tension en la parte central del trozo, se retorne suavemente a lo incierto, a lo indefinido, como acontece en la curiosa y vigorosa Fantasía para órgano en Sol Mayor del vol. IV (Ed. Peters) de Bach. (BAS, 1986, p. 327) ${ }^{18}$

18 Fantasia deve conter uma afirmação tal que permita satisfazer plenamente o sentido musical; seja convergindo o todo para o final como uma onda que emerge ou como uma sucessão de aspirações sempre ascendentes; seja, depois de atingir sua tensão máxima na parte central da peça, voltando suavemente para o incerto, para o indefinido, como acontece na curiosa e vigorosa Fantasia para Órgão em Sol Maior de Bach. (Tradução nossa) 
O segundo movimento descrito por Bas ajusta-se de modo bastante peculiar à última alternância do livro: à rígida e delimitada forma-sonata da Parte IV, que narra o beijo (de mão!) das sombras-amantes, segue-se a Parte V, que contém os poemas mais longos e descritivos, representando um retorno a estruturas e temáticas mais diluídas e indefinidas.

A proposta de ler Divina Quimera como uma fantasia mostra-se, pois, válida e prolífica.

\section{CONCLUSÃO}

Tendo estabelecido o ritmo como ponto de encontro entre Mallarmé e Eduardo Guimaraens, aproximamos o livro Divina Quimera da forma musical fantasia, que permitiria significativa alternância entre partes fluidas e partes mais fixas. Essa ordenação do material poético dialogaria com a configuração rítmica de Poésies, de Mallarmé, também composta em alternância, cortes e equilíbrio, e estaria resumida na seguinte citação de Mallarmé:

Uma ordenação do livro de versos aponta inata ou por toda parte, elimina o acaso; [...] [no volume] motivos de mesmo jogo se equilibrarão, balanceados, a distância, nem o sublime incoerente da colocação em página romântica nem essa unidade artificial, outrora, medida em bloco no livro. Tudo se torna suspense, disposição fragmentária com alternância e face a face, concorrendo para o ritmo total, o qual seria o poema calado, nos braços; somente traduzido, de certa maneira, por cada pingente. (MALLARMÉ, 2010, p. 165)

Em Divina Quimera cada pingente cintila e contém a natureza do conjunto. Todavia, olhar para os poemas ou para as partes isoladamente não permitiria dar conta da radicalidade da proposta formal do livro: nem o sublime incoerente do álbum romântico nem a unidade artificial medida em blocos, mas suspense, alternância e equilíbrio de motivos, balanceados, concorrendo para o ritmo total. 
Published in 1916, Eduardo Guimaraens' book of poems Divina Quimera (18921928) establishes, in his many references, relationships with the works and texts critical of Charles Baudelaire (1821-1867), Edgar Allan Poe (1809-1849), Stéphane Mallarmé (1842-1898), among others. Its configuration, based on the alternation of character of the five parts, allows us to bring it closer to the fantasy musical form, while "redivive" Mallarmés project of incorporating the anatomy of music into the Letters, choosing the rhythm (and not the logical progression) as organizing principle of the collection.

KeYwords: rhythm; fantasy (music); Stéphane Mallarmé (1842-1898); Eduardo Guimaraens (1892-1928).

\section{Mallarmé Redivivo en Eduardo Guimaraens}

\section{RESUMEN}

Publicado en 1916, el libro de poemas Divina Quimera, de Eduardo Guimaraens (1892-1928) establece, en sus numerosas referencias, relaciones con las obras y los textos críticos de Charles Baudelaire (1821-1867), Edgar Allan Poe (18091849), Stéphane Mallarmé (1842-1898), entre otros. Su configuración, basada en la alternancia de carácter de las cinco partes, nos permite aproximarlo de la forma musical fantasía, al mismo tiempo en que "redivive" el proyecto de Mallarmé de incorporar en las letras la anatomía de la música, eligiendo el ritmo (y no la progresión lógica) como principio organizador de la colección.

Palabras Clave: ritmo; fantasía (música); Stéphane Mallarmé (1842-1898); Eduardo Guimaraens (1892-1928).

\section{REFERÊNCIAS}

AGAMBEN, Giorgio. Estâncias: a palavra e o fantasma na cultura Ocidental. Tradução Selvino José Assmann. Belo Horizonte: Editora UFMG, 2007. 
BAS, Julio. Tratado de la Forma Musical. Tradução Nicolás Lamuraglia. Buenos Aires: Ricordi, 1986.

BALAKIAN, Anna. O simbolismo. Tradução José Bonifácio A. Caldas. São Paulo: Perspectiva, 2000.

BAUDELAIRE, Charles. As flores do mal. Tradução, introdução e notas de Ivan Junqueira. 6. ed. Rio de Janeiro: Nova Fronteira, 1985.

BERARDINELLI, Alfonso. Da poesia à prosa. Tradução Maurício Santana Dias. São Paulo: Cosac Naify, 2007.

BORDINI, Maria da Glória. A Divina Quimera como repressão do desejo. Letras de hoje, v. 15, n. 2, 1980.p. 72 a 85. Disponível em:

<http://revistaseletronicas.pucrs.br/fefid/ojs/index.php/fale/issue/ view/861>. Acesso em: 27 mar. 2019.

CARDOSO, Zélia de Almeida. A teoria poética de Mallarmé. Língua e Literatura, [s.l.], v. 5, p.411-421, 28 dez. 1976. Disponível em: <http://www.revistas.usp. br/linguaeliteratura/article/view/113817>. Acesso em: 30 mar. 2019.

CHÂTELAIN, François. La mise en scène de la Fiction: réflexions autour de la structure du recueil des Poésies de Mallarmé. Romantisme, n. 111, p. 89-105, 2001. Disponível em: <http://www.persee.fr/doc/roman_0048-8593_2001_ num_31_111_1006>. Acesso em: 25 mar. 2019.

DELÈGUE, Yves. Mallarmé, le sujet de la poésie. Revue d'histoire littéraire de la France, v. 101, p. 1423-1432, 2001/5. Disponível em: <http://www.cairn.info/ revue-d-histoire-litteraire-de-la-france-2001-5-page-1423.htm>. Acesso em: 04 mar. 2019.

EVANS, David. Rhythm, Illusion and the Poetic Idea: Baudelaire, Rimbaud, Mallarmé. Amsterdã: Rodopi, 2004. 355 p.

FRANCHETTI, Paulo. O Convite à Viagem. Notas sobre o exótico nas Flores do $\mathrm{Mal}$ [Breve especulação sobre a estrutura da primeira edição das Flores do Mal]. Disponível em: <http://paulofranchetti.blogspot.com.br/2012/07/notas-deleitura-das-flores-do-mal-de.html>. Acesso em: 07 jan. 2017.

FRIEDRICH, Hugo. Estrutura da lírica moderna: da metade do século XIX a meados do século XX. Tradução Marise M. Curioni. São Paulo: Livraria Duas Cidades, 1991. 
GUIMARAENS, Eduardo. A Divina Quimera. 2. ed. Edição definitiva com prefácio de Mansueto Bernardi. Porto Alegre: Livraria do Globo, 1944. 443 p.

. Divina Chimera. 1. ed. Rio de Janeiro: Oficina Tipográfica Apollo. Vieira da Cunha \& Cia, 1916, 107 p. (Desenhos de Correia Dias).

HURET, Jules. Enquête sur l'évolution littéraire. Paris: BibliothèqueCharpentier, 1891. p. 55-65.

KIEFER, Bruno. Elementos da linguagem musical.3. ed. Porto Alegre: Movimento, 1979.

LAWLER, James R. The Poet and the Chimæra: Duality in Baudelaire's "La Mort”. LittéRéalité, [S.1.], v. 3, n. 1, maio 1991. Disponível em: <http://litte. journals.yorku.ca/index.php/litte/article/view/26359/24356>. Acesso em: 25 jun. 2017.

. Poetry and Moral Dialetic: Baudelaire's "secret architecture" of Les Fleurs du Mal. Madison: Fairleigh Dickinson University Press, 1997.217 p.

MALLARMÉ, Stéphane. Le tombeau d'Edgar Poe/A tumba de Edgar Poe. Tradução Augusto de Campos. In: - Mallarmé. Tradução Augusto de Campos, Décio Pignatari e Haroldo de Campos. São Paulo, SP: Edusp \& Perspectiva, 1975.

. Divagações. Tradução e apresentação de Fernando Scheibe.

Florianópolis: Ed. da UFSC, 2010.270 p.

MARCON, Itálico. Eduardo Guimaraens ou da Plenitude poética. Nova Renascença, v. IX, p. 326-342, 1989/1990.

NIETZSCHE, Friedrich. Os pitagóricos. In: SOUZA, José Cavalcante de (Org.). Pré-socráticos: fragmentos, doxografia e comentários. Tradução Rubens Rodrigues Torres Filho. São Paulo: Nova Cultural, 1999. p. 62-64.

POLLICINO, Simona. La notion de rythme entre poésie et musique. Synergies Espagne, n. 4, p. 35-41, 2011.

RICIERI, Francine (Org.). Antologia da poesia simbolista e decadente brasileira. São Paulo: Companhia Editora Nacional/Lazuli Editora, 2007. .Eduardo Guimaraens e Dante. In: CONGRESSO INTERNACIONAL DA ABRALIC, 11., 2008. Anais... Disponível em: 
<http://www.abralic.org.br/eventos/cong2008/AnaisOnline/simposios/ pdf/014/FRANCINE_RICIERI.pdf>. Acesso em: 06 nov. 2016.

$* * * *$

Submetido em 30 de abril de 2019

Aceito em 05 de julho de 2019

Publicado em 15 de outubro de 2019 